
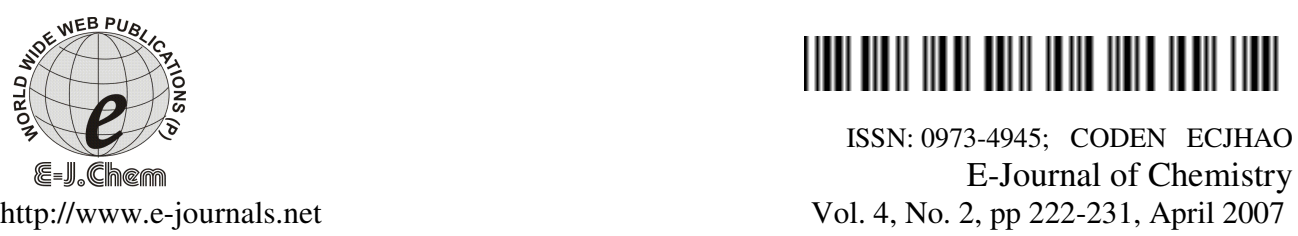

\title{
Synthesis and Characterization of Some New Thermal Stable Polymers - Polymerization of $\mathrm{N}$-[4-N'-(Benzylamino-carbonyl)phenyl]maleimide
}

\author{
B. L. HIRAN* JYOTI CHADHARY, S. N. PALIWAL, \\ SURESH MEENA and P. R. CHAUDHARY \\ Chemical Kinetics and Polymer Research Laboratory, \\ Department of Chemistry, \\ M. L. S. University, Udaipur (Raj.) India.313 001. \\ Email: hiranbl@rediffmail.com
}

Received 14 October 2006; Accepted 15 November 2006

\begin{abstract}
This article describes the synthesis and characterization of homopolymer (H-BCPM) of $\mathrm{N}$-[4-N'-(benzylamino-carbonyl) phenyl] maleimide (N-BACPMI) and copolymer (C-BCPM) of N-BACPMI with $n$ butyl acrylate (BA). The new monomer was synthesized from $p$-aminobenzoic acid, maleic anhydride and benzylamine. The homopolymerization of $\mathrm{N}$ BACPMI is initiated by free radical using AIBN in THF solvent at $65{ }^{\circ} \mathrm{C}$. Radical copolymerization of N-BACPMI with BA, initiated by AIBN, was performed in THF solvent using equimolar amount. Effect of the different free radical initiator AIBN, BPO and solvents $p$-Dioxane, THF, DMF and DMSO was studied. Homopolymer and Copolymer were characterized by intrinsic viscosity, solubility test, FT-IR, ${ }^{1} \mathrm{H}-\mathrm{NMR}$ spectral analysis and elemental analysis. Thermal behaviour was studied by Thermo gravimetric analysis.
\end{abstract}

Keywords: Radical polymerization, N-[4-N'-(benzylamino-carbonyl) phenyl] maleimide, $n$-butyl acrylate, Characterization.

\section{Introduction}

Currently, polymers with defined architective and controlled composition are of considerable interest for their academic and industrial uses ${ }^{1-3}$. There is a considerable interest not only in the synthesis of new type of the plastic materials but also in the modification of exiting polymers in order to vary its properties to meet requirements for new 
applications under unusual working conditions ${ }^{4-6}$. Most aromatic polyimides produced by the thermal solid-state phase imidization show insolubility and infusibility, which make processing difficult. These undesirable properties, which limit wider application of the polyimides, are due to their chain rigidity as well as to poor defined molecular architectures. Addition type polyimides were developed mainly to overcome processing disadvantages ${ }^{7-9}$. During the past several years many publications appeared describing the chemical modification of various vinyl polymers such as styrene or methyl methacrylate by an addition $\mathrm{N}$-substituted maleimide $\mathrm{e}^{10-22}$. In order to investigate the possibility of obtaining better polymers from $\mathrm{N}$-substituted maleimide, we report here the synthesis of $\mathrm{N}-\left[4-\mathrm{N}^{\prime}-\right.$ (benzylamino-carbonyl) phenyl] maleimide monomer and its polymerization and copolymerization with n-butylacrylate. It was observed that such copolymers have better thermal stability than the polymers of vinyl monomers. However, polymerization of $\mathrm{N}$ BACPMI has not been investigated. The goal of this study was assessment of polymerization of N-BACPMI, whose incorporation into the backbone chain could present a considerable and promising interest. The N-BACPMI monomer is a five member planer ring which completely hinder the rotation of the imide residue around the back bone chain of the macromolecules and expected to produce copolymers with a great structures stiffness as well as higher thermal stabilities. The physical, spectral and thermal properties have been studied in order to characterize the homo and copolymer.

\section{Experimental}

\section{Materials}

p-Aminobenzoic acid and maleic anhydride were recrystallized from acetone. n-Butylacrylate $(\mathrm{CDH})$ was shaken two to three times with $5 \% \mathrm{NaOH}$ to eliminate hydroquinone inhibitor, dried over anhydrous $\mathrm{CaCl}_{2}$ for $6 \mathrm{~h}$ and distilled ${ }^{23}$. The head and tail fractions were discarded. AIBN (2,2'-azobis-isobutironitrile (spectorchem.)) was recrystallized twice from methanol prior to use. BPO (benzoyl peroxide $\mathrm{CDH}$ ) was used as received. THF was purified by distillation after being refluxed for $2 \mathrm{~h}$ in the presence of sodium ${ }^{23}$. Dioxane and DMSO were used after distillation. DMF and methanol used in the present work were of analytical grade and were used as received.

\section{Measurements}

${ }^{1} \mathrm{H}-\mathrm{NMR}$ spectra of monomer and polymer samples were taken in DMSO- $d_{6}$ on a Bruker DPX-200/DPX-300 spectrometer at 200/300 MHz. The internal reference used was TMS. FT-IR spectra of the monomer and polymer sample were recorded on a Shimadzu $8201 \mathrm{PC}\left(4000-400 \mathrm{~cm}^{-1}\right)$ FT-IR spectrometer, using KBr pellet technique. The viscosity measurements were carried out in DMF at $30 \pm 0.2{ }^{\circ} \mathrm{C}$, using an Ubbelohde suspended level viscometer. Elemental analysis was made on Carlo Erba Model NA 500 series analyzer. The thermograms in air were obtained on a Mettler TA-3000 system, at a heating rate of $10{ }^{\circ} \mathrm{C} / \mathrm{min}$

\section{Preparation of $N$-[4- $N^{\prime}-($ benzyl amino-carbonyl)phenyl]maleimide (N-BACPMI)}

N-BACPMI monomer was synthesized in four steps ${ }^{24-26}$ from maleic anhydride, $p$-aminobenzoic acid and benzylamine (described below and shown in Scheme 1).

\section{$N$ - (4-Carboxyphenyl) maleiamic Acid (p-CPMA)}

A solution of maleic anhydride (19.62g, $0.2 \mathrm{~mol})$ in DMF was gradually added over a period of 10 minute to a well-stirred solution of $p$-aminobenzoic acid $(27.42 \mathrm{~g}, 0.2 \mathrm{~mol})$ in DMF. 
Then the mixture was stirred for $5 \mathrm{~h}$ at room temperature. The resulting solution was poured into a large amount of crushed ice to precipitate crude $p$-CPMA. The crude $p$-CPMA was filtered, dried and then recrystallized from ethanol to obtain pure $p$-CPMA in $85 \%$ yield, $\mathrm{mp}$ $222{ }^{\circ} \mathrm{C}$ (lit. mp..225-226 ${ }^{\circ} \mathrm{C}$ ) ${ }^{20}$. The IR spectrum showed absorptions at 3500-2500 (carboxylic acid O-H), 3317, 1544 (amide N-H), 1697 (carboxylic acid and amide), 1288 (carboxylic acid $\mathrm{C}-\mathrm{O}), 848(\mathrm{CH}=\mathrm{CH}), 675\left(\mathrm{C}-\mathrm{H}\right.$ bending) in $\mathrm{cm}^{-1} .{ }^{1} \mathrm{H}-\mathrm{NMR}(300 \mathrm{MHz}$, TMS, DMSO- $\left.d_{6} \delta \mathrm{ppm}\right): 10.45(\mathrm{~s}, 1 \mathrm{H}, \mathrm{COOH}) ; 7.4 \& 7.8(2 \mathrm{~d}, \mathrm{j}=8.58 \mathrm{~Hz}$ in phenyl); $6.16(\mathrm{~s}$, $2 \mathrm{H}, \mathrm{CO}-\mathrm{CH}=\mathrm{CH}-\mathrm{CO}) ; 3.27$ (s, $1 \mathrm{H}$ in $-\mathrm{NH}) ; 11.45$ (s, 1H, $\mathrm{COOH})$.

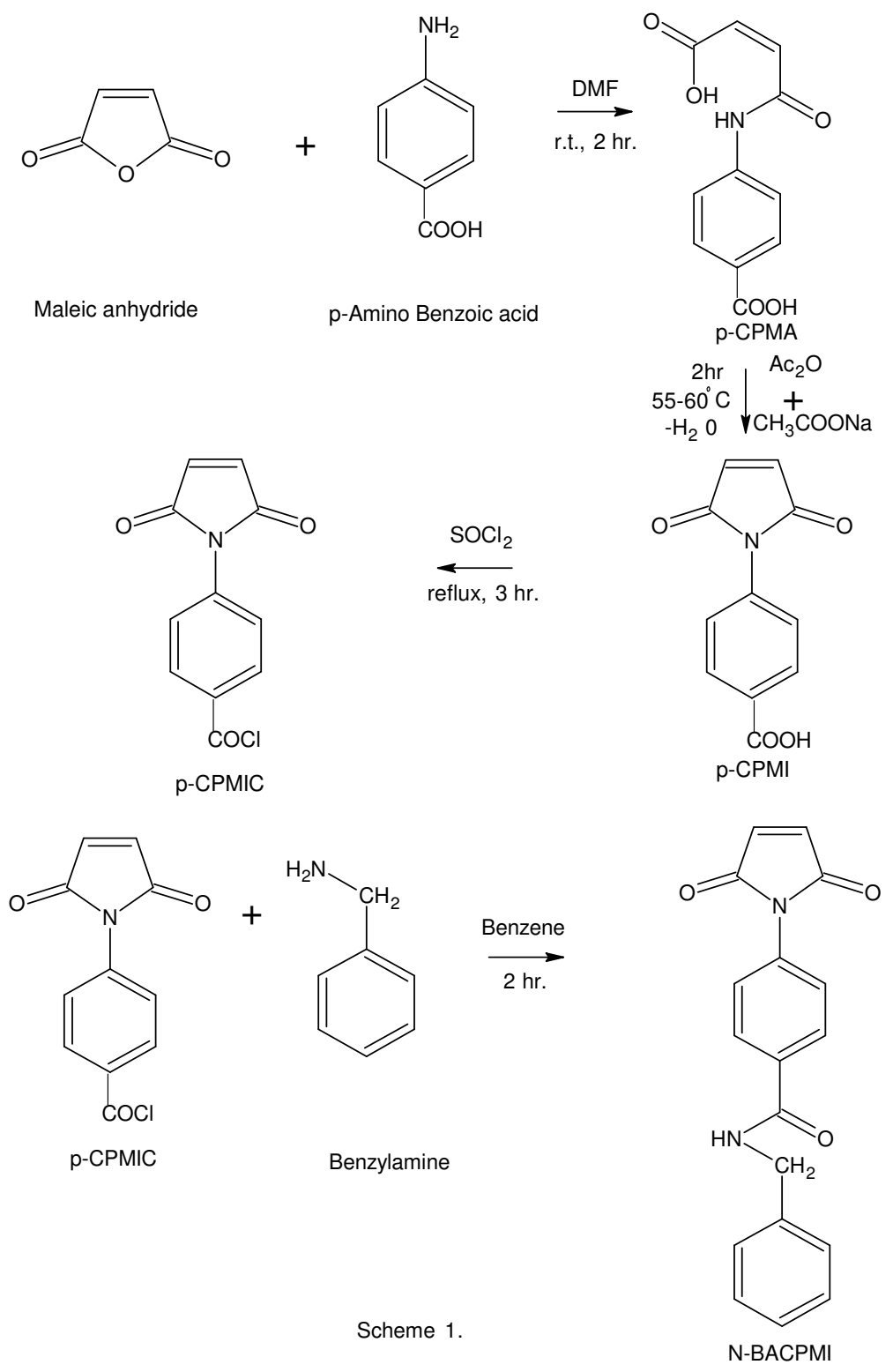




\section{$N$-(4-Carboxyphenyl) maleimide ( $p$-CPMI)}

A mixture of $23.5 \mathrm{~g}(0.1 \mathrm{~mol}) p$-CPMA, $16.4 \mathrm{~g}(0.2 \mathrm{~mol})$ sodium acetate and $120 \mathrm{~mL}$ acetic anhydride were stirred for $2 \mathrm{~h}$ at $55-60{ }^{\circ} \mathrm{C}$. Cooled reaction mixture was poured into large amount of crushed ice, light yellow mass obtained of $p$-CPMI was filtered and dried at 60 $70^{\circ} \mathrm{C}$ and the recrystallized from methanol obtaining the product in a $75 \%$ yield with $\mathrm{mp}$ $231^{\circ} \mathrm{C}$ (lit. mp. $225-228^{\circ} \mathrm{C}^{27}$ and $231^{\circ} \mathrm{C}^{28}$ ). The IR spectrum showed absorption $3500-2500$ (Carboxylic acid $\mathrm{O}-\mathrm{H}), 1774,1714$ (C=O stretch, 5-membered imide ring), 1215 (Carboxylic acid C-O), 1598, 1514(Aromatic C=C), and 952, $698(\mathrm{CH}=\mathrm{CH}) \mathrm{cm}^{-1} .{ }^{1} \mathrm{H}-\mathrm{NMR}$ (300MHz, TMS, DMSO- $\left.d_{6} \delta \mathrm{ppm}\right): 12.45$ (s, $\left.1 \mathrm{H}, \mathrm{COOH}\right) ; 8.07$ and 8.03 (2d, 4H, Phenyl); 7.5 and 7.9 (s, 2H, OC-CH=CH-CO).

\section{N-[4-(Chlorocarbonyl) phenyl] maleimide (p-CPMIC)}

A mixture of $p$-CPMI $(17.1430 \mathrm{gm}, 0.079 \mathrm{~mol})$ and thionyl chloride $(150 \mathrm{~mL}, 2.07 \mathrm{~mol})$ was refluxed at $80^{\circ} \mathrm{C}$ for $2 \mathrm{~h}$. The unreacted thionyl chloride was evaporated off and residual product was recrystallized from benzene to obtained pure light yellow crystals of acid chloride. It was obtained in $80 \%$ yield, $\mathrm{mp} 157^{\circ} \mathrm{C}$ (lit. $\mathrm{mp} 153-157^{\circ} \mathrm{C}^{27}$ and $153^{\circ} \mathrm{C}^{30}$ ). The IR spectrum showed absorption at $1747(\mathrm{COCl}), 1747,1716$ (CONCO), $1610(\mathrm{C}=\mathrm{C}), 883,840$ $(\mathrm{CH}=\mathrm{CH}) \mathrm{cm}^{-1} .{ }^{1} \mathrm{H}-\mathrm{NMR}\left(300 \mathrm{MHz}, \mathrm{TMS}, \mathrm{DMSO}-d_{6} \delta \mathrm{ppm}\right): 8.07$ and $8.03(2 \mathrm{~d}, 4 \mathrm{H}$ in phenyl); 7.5 and 7.9 (s, 2H, OC-CH=CH-CO).

\section{$N-B A C P M I$}

A benzene solution of benzylamine $(0.5 \mathrm{~mol}$ in $100 \mathrm{ml}$ benzene) was added drop wise to a CPMIC $(11.75 \mathrm{gm} 0.5 \mathrm{~mol})$ solution in benzene $(100 \mathrm{~mL})$ at $0-5^{\circ} \mathrm{C}$ and the mixture was stirred at room temperature for $2 \mathrm{~h}$. The precipitated product was filtered, washed with water, dried and then recrystallized twice from ethanol to obtain pure N-BACPMI in a $62 \%$ yield, $\mathrm{mp}$ $165^{\circ} \mathrm{C}$.The purity and structure of the monomer was ascertained by elemental $(\mathrm{C}, \mathrm{H}, \mathrm{N})$ analysis, IR and ${ }^{1} \mathrm{H}$ NMR study. Anal.calcd.for C18H14O3N2, C, 70.59; H, 4.57; N, 9.15; Found C, 69.98; H, 4.01; N, 8.68. FT-IR: 3400-3300 (-NH) , 1633,1508, (CONH), 1770, 1709 (CONCO) 1399(C-N), 950, $694(\mathrm{CH}=\mathrm{CH}) \mathrm{cm}^{-1} .{ }^{1} \mathrm{H}$ NMR $\left(300 \mathrm{MHz}, \mathrm{TMS}, \mathrm{DMSO}-d_{6}\right.$, $\delta \mathrm{ppm}) 7.20(\mathrm{~s}, 2 \mathrm{H}, \mathrm{CH}=\mathrm{CH}) ; 8.01-7.98(\mathrm{~d}, 2 \mathrm{H}$ in phenyl ring meta- to maleimido); 7.807.77 (d, $2 \mathrm{H}$ in phenyl ring ortho- to maleimido); $9.48(\mathrm{~s}, 1 \mathrm{H}, \mathrm{CONH}) ; 7.52-7.47$ (d, 2H in phenyl ring ortho- to amide); 7.38-7.29 (t, $2 \mathrm{H}$ in phenyl ring meta- to amide); 4.51 (s, $2 \mathrm{H}$ in methylene group) and 7.28-7.25 (t, $1 \mathrm{H}$ in phenyl ring para- to amide).

\section{Polymerization}

\section{Homopolymerization}

Radical homopolymerization of N-BACPMI $(0.03 \mathrm{~mol}, 9.18 \mathrm{gm})$, were carried out with AIBN as a free radical initiator in THF $(120 \mathrm{~mL})$, in a round bottom flask. Reaction mixture was refluxed at $65^{\circ} \mathrm{C}$ for $24 \mathrm{~h}$. The homopolymer (H-BCPM) was isolated by precipitation in methanol containing water. The precipitated homopolymer was washed with methanol several times and dried in a vaccum oven. A summary of polymerization conditions and physical characteristics of H-BCPM are presented in Table 1. Various homopolymer samples were obtained using different solvent-initiator combination. The percentage yields of homopolymer samples, using different solvent/initiator systems, are presented in Table 2 . 
<smiles>O=C(NCc1ccccc1)c1ccc(N2C(=O)C=CC2=O)cc1</smiles>

N-BACPMI

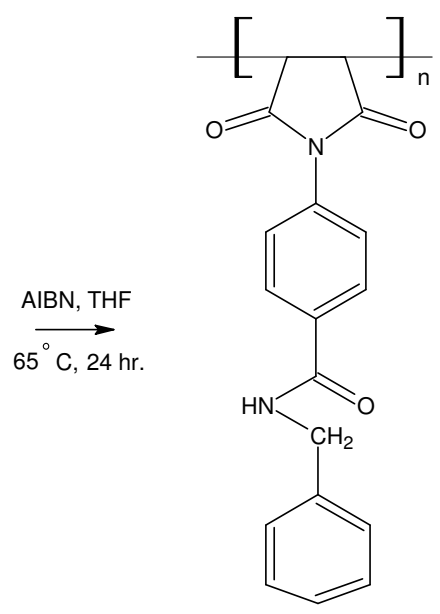

H-BCPM

\section{Copolymerization}

The reaction mixture was carried out in the round bottom flask in equimolar amount of $\mathrm{N}$ BACPMI and n-butylacrylate in $110 \mathrm{~mL}$ THF were refluxed after adding $25 \mathrm{mg}$ AIBN at $65^{\circ} \mathrm{C}$ for $12 \mathrm{~h}$.The copolymer (C-BCPM) was precipitated in methanol and water mixture. The precipitated copolymer was filter and washed with methanol several times and dried. A summary of polymerization conditions and physical characteristics of C-BCPM are presented in Table 1.

Various copolymer samples were obtained using different solvent-initiator combination. The percentage yield of copolymer samples, using different solvent/initiator systems are presented in Table 2.<smiles>O=C(NCc1ccccc1)c1ccc(N2C(=O)C=CC2=O)cc1</smiles>

N-BACPMI

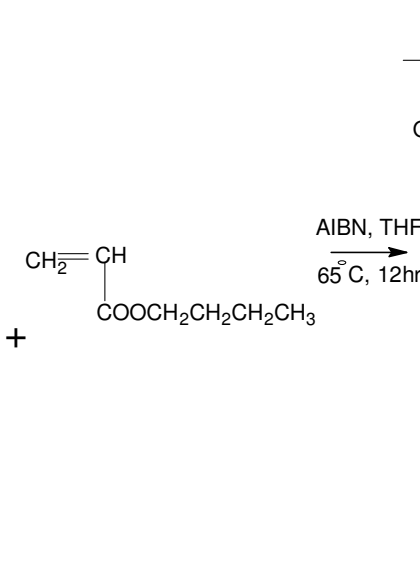

n-butyl acrylate

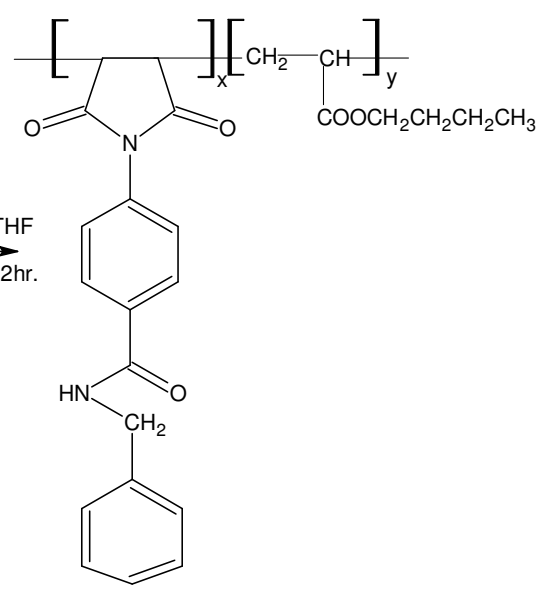

C-BCPM 
Table 1. Radical polymerization and copolymerization of N-BACPMI and $n$-butyl acrylate in THF at $65^{\circ} \mathrm{C}$.

\begin{tabular}{lcccccl}
\hline $\begin{array}{l}\text { Polymer } \\
\text { Code }\end{array}$ & $\begin{array}{c}\text { Feed mol } \\
\text { fraction of } \\
\text { N-BACPMI }\end{array}$ & $\begin{array}{c}\text { polymerization } \\
\text { Time }(\mathrm{h})\end{array}$ & $\begin{array}{c}\text { Yield } \\
(\%)\end{array}$ & $\begin{array}{l}{[\eta]} \\
(\mathrm{dL} / \mathrm{g})\end{array}$ & Appearance \\
\hline H-BCPM & 1.0 & 24 & 46.58 & 8.68 & 0.157 & Cream \\
C-BCPM & 0.5 & 12 & 51.65 & 6.35 & 0.200 & white \\
\hline
\end{tabular}

\section{Results and Discussion}

\section{Solvent-Initiator System}

Since free radical homo and copolymerization of maleimides is known to be useful on the synthesis of polymaleimides. This method was applied to their preparation from N-BACPMI and vinyl monomers to find suitable condition in which to prepare homo \& copolymaleimide with relatively high yield. The effect of initiator \& solvent were investigated in details. The effect of reaction solvents and initiator on yield of H-BCPM and C-BCPM was formed in different pairs of solvent initiator is summarized in Table 2.

Table 2.Percentage yield of homo and copolymaleimide in various solvent-initiator systems.

\begin{tabular}{lllll}
\hline \multirow{2}{*}{ Solvent } & \multicolumn{2}{c}{ AIBN } & \multicolumn{2}{c}{ BPO } \\
\cline { 2 - 5 } & H-BCPM & C-BCPM & H-BCPM & C-BCPM \\
& Yield (\%) & Yield (\%) & Yield (\%) & Yield (\%) \\
\hline THF & 46.58 & 51.65 & 45.98 & 49.05 \\
$p$-Dioxane & 45.26 & 44.26 & 45.69 & 47.04 \\
DMF & 28.45 & 35.25 & 27.58 & 39.26 \\
DMSO & 43.25 & 48.02 & 38.14 & 49.28 \\
\hline
\end{tabular}

The percentage yield of the H-BCPM in the AIBN-DMF system was poor compared to AIBN-dioxane and BPO-dioxane. AIBN-DMSO system gave better yield of C-BCPM over the AIBN-dioxane \& BPO-dioxane system. AIBN-THF system of both polymerizations gave better yield then other solvent - initiator system including BPO-THF system. Examination of all the aspect AIBN-THF system was most suitable for the present homo \& copolymerization process.

\section{Effect of Time on polymer yield}

The effect of reaction solvents and time on yield of H-BCPM and C-BCPM was formed in different time is summarized in Table 3.

Table 3. Percentage yield of homo and copolymaleimide in different time.

\begin{tabular}{ccccccccc}
\hline \multirow{3}{*}{ Solvent } & \multicolumn{3}{c}{ H-BCPM } & \multicolumn{5}{c}{ C-BCPM } \\
& \multicolumn{3}{c}{ Yield (\%) } & \multicolumn{4}{c}{ Yield (\%) } \\
\cline { 2 - 10 } & $12 \mathrm{~h}$ & $18 \mathrm{~h}$ & $24 \mathrm{~h}$ & $30 \mathrm{~h}$ & $12 \mathrm{~h}$ & $18 \mathrm{~h}$ & $24 \mathrm{~h}$ & $30 \mathrm{~h}$ \\
\hline THF & 35.65 & 40.56 & 46.58 & 47.56 & 51.65 & 52.52 & 53.25 & 53.69 \\
\hline
\end{tabular}

Table 3 revel that N-BCPMI gave better yield of homopolymerization in $24 \mathrm{~h}$ in THF solvent and copolymerization in $12 \mathrm{~h}$. 


\section{Solubility}

Table 4 summarizes the relative solubilities of homo and copolymer samples in number of polar and non-polar solvents at $30{ }^{\circ} \mathrm{C}$. The investigated homo and copolymer both samples are soluble in THF, DMF, DMSO, ethyl acetate, acetone, chloroform, dichloromethane and Cyclohexanone. Individual homopolymer is soluble in $p$-dioxane and partially soluble in carbon tetrachloride. Solubility behaviour in the later solvents depends on the composition of polymer. The solubility of homopolymer is more than copolymer in the solvent taken.

Table 4. Solubility Behaviour of monomer, homopolymer and copolymer in Polar and Non-polar Solvents at $30^{\circ} \mathrm{C}$.

\begin{tabular}{lccc}
\hline Solvent & N-BACPMI & H-BCPM & C-BCPM \\
\hline Acetone & IS & S & S \\
Cyclohexanone & IS & S & S \\
Dioxane & S & S & IS \\
THF & S & S & S \\
DMF & S & S & S \\
Dichloromethane & IS & S & S \\
DMSO & S & S & S \\
Chloroform & IS & S & S \\
CCl & IS & PS & IS \\
Xylene & IS & IS & IS \\
Toluene & IS & IS & IS \\
Methanol & IS & IS & IS \\
& & &
\end{tabular}

S=Soluble, IS= Insoluble, $\mathrm{PS}=$ Partially Soluble

\section{Intrinsic Viscosity [ $\eta]$}

Intrinsic viscosity $[\eta]$ is a measure of hydrodynamic volume and depends on molecular weight as well as on the size of the polymer coil in a given solution. The values of average [ $\eta$ ] in DMF solution at $30{ }^{\circ} \mathrm{C}$ are listed in Table 1 . The value of [ $\left.\eta\right]$ decreases from 0.200 to $0.157 \mathrm{dL} / \mathrm{gm}$ for copolymer to homopolymer. The value of [ $\eta]$ depends on the composition of N-BACPMI. Intrinsic viscosity of homopolymer is less then copolymer. It's indicating the content of N-BACPMI is increased then value of $\eta$ is decreased.

\section{Spectral characterization}

The FT-IR spectrum and ${ }^{1} \mathrm{H}-\mathrm{NMR}$ spectrum $\left(300 \mathrm{MHz}\right.$ in DMSO- $d_{6}$ ) of H-BCPM are shown following peak and chemical shift. The absence of a sharp band at $950 \mathrm{~cm}^{-1}$ and chemical shift $\delta$ at $7.32 \mathrm{ppm}$ due to $\mathrm{CH}=\mathrm{CH}$ in a monomer having a vinyl group, such as monomer $\mathrm{N}$ BACPMI, indicates the formation of polymer via vinyl group polymerization ${ }^{29,30}$.

The presence of absorption bands at 1770 and $1715 \mathrm{~cm}^{-1}$ due to symmetric and asymmetric stretching of $\mathrm{C}=\mathrm{O}$ in the five member imide ring indicates that the imide ring remained intact in the polymerization. The imide group is also confirmed from the bands observed at 1452(Ar- N stretch), 1368 (C-N stretch), 1164 (C-N-C), $1115 \mathrm{~cm}^{-1}$ and $750 \mathrm{~cm}^{-1}$. The broad medium intense band at $1668 \mathrm{~cm}^{-1}$, strong intense band at $1508 \mathrm{~cm}^{-1}$ and a medium band at $1539 \mathrm{~cm}^{-1}$ correspond to the amide group . The broad stretching band at $3309 \mathrm{~cm}^{-1}$ represent secondary amine (-NH). 
The $\delta$ observed at $7.23 \mathrm{ppm}$ due to $\mathrm{CH}=\mathrm{CH}$ in the monomer has shifted to $3.4-4.1 \mathrm{ppm}$ in the polymer, as a result of the formation of a semi flexible poly (substituted methine) $[\mathrm{CH}-\mathrm{CH}]_{\mathrm{n}}-$ group $^{31}$. The $\delta$ for methine $-(\mathrm{CH}-\mathrm{CH})$ - protons has been reported in the range from 3.0-5.0 ppm depending upon the substitution in maleimide. The value of $\delta$ in the range 3.0-4.0 for poly [ $\mathrm{N}-\left[4-\mathrm{N}^{\prime}-\left(\alpha-\right.\right.$ methylbenzyl) aminocarbonyl phenyl] maleimide ${ }^{26}, 3.5-4.5$ for poly ( $\mathrm{N}$ - alkyl substituted phenyl) maleimide ${ }^{31}$ and poly [N-[4-(cholesteroxy carbonyl phenyl) maleimide $]^{32}$ have been reported . The broad peak at 7.0 -8.1 ppm corresponds to $9 \mathrm{Ar}-\mathrm{H}$.

The major characteristic absorption bands are observed at 3400- 3300 (broad, -NH stretch $), 1774,1716(\mathrm{C}=\mathrm{O}$ symmetric and asymmetric stretch in a five member imide ring and $\mathrm{C}=\mathrm{O}$ stretch of ester), 1603, 1528 (aromatic, $\mathrm{C}=\mathrm{C}$ and amide group). These characteristic bands confirm that units of both the monomers N-BACPMI and $n$-butyl acrylate are present in the copolymer samples.

The ${ }^{1} \mathrm{H}$ NMR spectra of the copolymer showed the following chemical shifts. The $\delta$ at 7.86$7.84 \mathrm{ppm}$ is of $2 \mathrm{Ar}-\mathrm{H}$, ortho- to $\mathrm{N}$ of imide group while at 7.65-7.62 ppm for $2 \mathrm{Ar}-\mathrm{H}$, meta- to $\mathrm{N}$-of imide group. The $\delta$ at 7.37-7.36 ppm is for $2 \mathrm{Ar}-\mathrm{H}$, ortho- to $\mathrm{N}$ of the amide group; at $\delta$ 7.3$7.5 \mathrm{ppm}$ is for $2 \mathrm{Ar}-\mathrm{H}$, para- to $\mathrm{N}$ of the amide group and 7.26-7.23ppm is for $2 \mathrm{Ar}-\mathrm{H}$, meta-to $\mathrm{N}$ of amide group . A $\delta$ at 9.55 (broad) ppm appeared for $1 \mathrm{H}$ in -CONH- group of N-BACPMI segment and $\delta$ observed at $4.47 \mathrm{ppm}$ is $2 \mathrm{H}$ in $-\mathrm{CH}_{2}$ of benzyl segment. The $\delta$ observed at 3.4-3.7 ppm corresponds to overlapping of $2 \mathrm{H}-(\mathrm{CH}-\mathrm{CH})$ - in the polymer main chain and $2 \mathrm{H}\left(-\mathrm{OCH}_{2}\right)$ of BA segment. The $\delta$ in the range 1.0-2.4 ppm is of $2 \mathrm{H}$ of methylene group and $1 \mathrm{H}$ of $-\mathrm{CH}-$ group while at $0.96-1.57 \mathrm{ppm}$ for $7 \mathrm{H}$ of butyl group accept $-\mathrm{OCH}_{2}$.

\section{Thermal Properties}

It is well known that polymaleimide is potential heat- and chemical-resistant material, so maleimide is widely used as a comonomer for modified polymeric systems. Only single step degradation at temperature of over $300{ }^{\circ} \mathrm{C}$ was observed for polymaleimide in TGA. The thermograms were obtained by heating homopolymer and copolymer sample in air $10^{\circ} \mathrm{C} / \mathrm{min}$. the typical TGA curve. The results of percentage weight loss suffered from $100^{\circ} \mathrm{C}$ to $600^{\circ} \mathrm{C}$ at 100 intervals are furnished in Table 6 .

The initial decomposition temperature Ti, temperature for maximum weight loss Tmax, and final decomposition temperature $\mathrm{T} f$ of first and second degradation steps are given in Table 5. The results in Table 5 indicate that the relative thermal stability on the basis of Ti follows on the order $\mathrm{H}-\mathrm{BCPM}>\mathrm{C}-\mathrm{BCPM}$.

As the content of N-BACPMI in the feed is $100 \%$ in the homopolymer began to decompose at higher $\mathrm{T} i$ and weight loss for the first step became smaller. The first step weight loss ranged from 40-42\%. The weight loss for the second step became larger increasing from $55-60 \%$. The total weight loss of $\mathrm{H}-\mathrm{BCPM}$ upto $600^{\circ} \mathrm{C}$ is $70 \%$.

The copolymer C-BCPM decomposes through a two-step procedure. As the copolymer sample content of N-BACPMI is $50 \%$, the copolymer began to decomposition at lower $\mathrm{T} i$ and weight loss for the first step became larger as compared to homopolymer. The first step weight loss was range to 60 to $65 \%$. The weight loss for second step is 23 to $30 \%$. The total weight loss of C-BCPM upto $600^{\circ} \mathrm{C}$ is $90-95 \%$.

Table 6 revels that weight loss was below 0.8 to $8 \%$ up to $300^{\circ} \mathrm{C}$ in copolymer sample $\& 100 \%$ content of N-BACPMI feed in homopolymer weight loss was below 0.1 to $2 \%$ up to $300^{\circ} \mathrm{C}$. The results in Table 5 indicate that the thermal stability tends to increases from the copolymer to homopolymer. 
Table 5. Thermal behaviour of homopolymer and copolymer.

\begin{tabular}{llllll}
\hline Polymer & $\begin{array}{c}\mathrm{T} i \\
\left({ }^{\circ} \mathrm{C}\right)\end{array}$ & $\begin{array}{l}\text { Tmax } \\
\left({ }^{\circ} \mathrm{C}\right)\end{array}$ & $\begin{array}{l}\mathrm{T} f \\
\left({ }^{\circ} \mathrm{C}\right)\end{array}$ & $\begin{array}{l}\text { Residue at } \\
500\left({ }^{\circ} \mathrm{C}\right)\end{array}$ \\
\hline H-BCPM & I & 288 & 360 & 415 & 45 \\
& II & 415 & 575 & 690 & \\
C-BCPM & I & 442 & 367 & 526 & 25 \\
& II & 526 & 593 & 660 & \\
\hline
\end{tabular}

Table 6. Percentage weight loss of homo and copolymer at various temperatures from the TGA.

\begin{tabular}{cccccc}
\hline \multirow{2}{*}{ Polymer } & $200{ }^{\circ} \mathrm{C}$ & $300{ }^{\circ} \mathrm{C}$ & $400{ }^{\circ} \mathrm{C}$ & $500{ }^{\circ} \mathrm{C}$ & $600{ }^{\circ} \mathrm{C}$ \\
\cline { 2 - 6 } & \multicolumn{5}{c}{ Weight loss, $(\%)$} \\
\hline H-BCPM & 0.7 & 25 & 45 & 55 & 70 \\
C-BCPM & 0.6 & 35 & 73 & 75 & 95 \\
\hline
\end{tabular}

\section{Conclusions}

Synthesis, through free radical polymerization, homopolymerization of N-BACPMI and copolymerization of N-BACPMI with n-butylacrylate has been investigated. The most suitable initiator-solvent pair for the homo and copolymerization was found to be AIBN-THF. The investigated homo and copolymaleimide show excellent solubility in THF, DMF, DMSO, ethyl acetate, chloroform, dichloromethane and cyclohexanone. The characterization of homo and copolymer was carried out through elemental analysis, IR and ${ }^{1} \mathrm{H}-\mathrm{NMR}$ spectral analysis. Homopolymer show good thermal stability then copolymer and it degrade is two-step.

\section{Acknowledgements}

We are thankful to CDRI Lucknow and SICART Vallabh-vidhyanager for analysis work. One of the authors (S.N.Paliwal) is thankful to UGC (New Delhi) for financial assistance.

\section{References}

1. Rizzardo E and Moad G J C, Edn, CRC, Boca Raton, FL, 1996, 5, 3834.

2. $\quad$ Rizzardo Matyjaszewski K, ACS Symp Ser 1998, 685, 2-30.

3. Colombani D, Prog Polym Sci 1997, 22, 1649-1720.

4. $\quad$ Nield E and Rose J B, U.S.Patent. 1972, 3, 652726.

5. Sato H, Jpn. Kokai. 1987, 87, 156115.

6. Masuko S, Takahara H and Yamamoto A, Jpn. Kokai. 1988, 88, 245413.

7. Cubbon R C P, Polymer, 1965, 6, 419-426.

8. Barrales-Rienda $\mathbf{J}$ and Gonzalez De La, Camp J L and Gonzalez Ramos, $J$. Macromol. Sci. Chem., 1997, A11, 267-286.

9. Kagawa K, Oishi T, Matsusaki K and Fujimoto M, Polymer, 1995, 36, 941-948.

10. Coleman Jr L E and Conrady J A, J. Polym. Sci. 1959, 38, 241.

11. Takase I, Fukushima N, Aida H and Yamada M, Kobunshi Kagaku, 1973, 30 (10), 632.

12. Barrales-Rienda J, Gonzalez de la, Campa, J I and Gonzalez Ramos J, J. Macromol. Sci. Chem. 1977, A11, 267.

13. Oishi T, Polym. J., 1981, 13, 65.

14. Patel J C and Patel M R, J. Macromol. Sci. Chem. 1983, A19, 801.

15. Patel J D and Patel M R, J. Polym. Sci. Polym. Chem. Ed. 1983, 21, 3027.

16. Nair C P R, J. Polym. Sci. Polym. Chem. Ed, 1992, 26, 47. 
17. Choudhary L and Varma D S, Varma I K and Wang F W, J. Therm.Anal. 1993, 39, 633

18. Bharel R, Choudhary V and Varma I K, J. Appl. Polym. Sci. 1994, 54, 2165.

19. Choudhary V and Mishra A, J. Appl. Polym. Sci., 1996, 62, 707.

20. Salman I A, Al-Sagheer F A and Elsabee M Z, J. Macromol. Sci. Pure \& Appl. Chem. A.1997, 34(7), 1207.

21. Ryttle A and Angew, Makromol. Chem.,1999, 67, 267.

22. Patel C B, Malek N and Oswal S L, J. Macromol, I. Sci. Part A Pure \& Appl.Chem. 2006, 43, 289-303.

23. Riddick J A, Bunger W B and Sakano T K, Organic Solvents Physical Properties and Methods of Purification. Wiley Interscience, NewYork, 1986.

24. Searle N E, Synthesis of N-Arylmaleimides. U.S. Patent ,1948, 2, 444536.

25. Hoyt A E and Benicewicz B C, J. Polym. Sci. Part A Polym. Chem. 1990, 28, 3403.

26. Oishi T and Fujimoto M, J. Polym. Sci. Part A Polym. Chem. 1992, 30, 1821.

27. Park J O and Jang S H, J. Polym. Sci, Part A: Polym. Chem., 1992, 30, 723-729.

28. Liu F J, Munukuila S, Livon, K and Lisoko G, J. Polym. Sci.: Part A: Polym. Chem., 1992, 30, 157-162.

29. Silverstain R M and Assler G C, John Wiley and Sons. Inc. New York. 1991.

30. Sadhir R K and Smith J D B, J. Polym. Sci. Polym. Chem. Ed., 1992, 30, 589-595.

31. Matsuoto A, Kubota T and Otsu T, Macromolecules, 1990, 23, 4508-4513.

32. Oishi T, Otsubo Y, Matsusaki K and Fujimoto M, Polymer, 1993, 34(7), 1504-1511. 


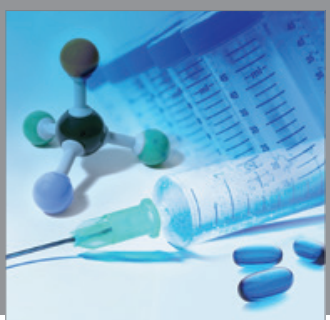

International Journal of

Medicinal Chemistry

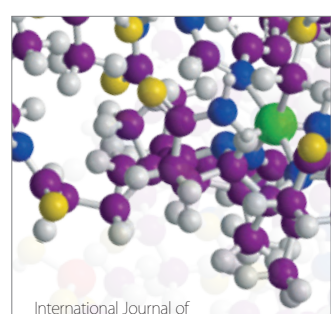

Carbohydrate Chemistry

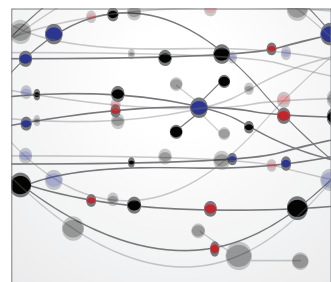

The Scientific World Journal
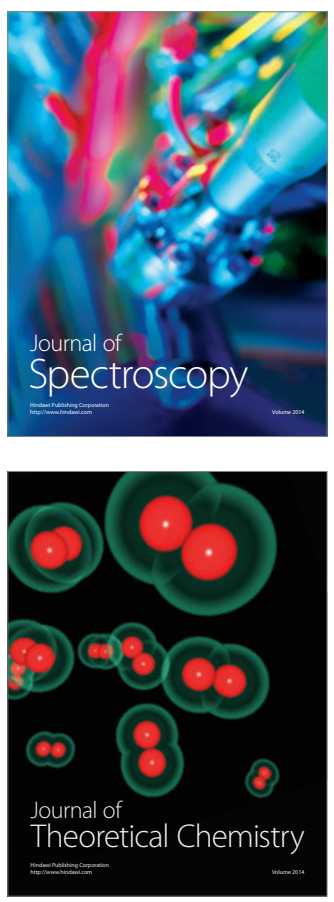
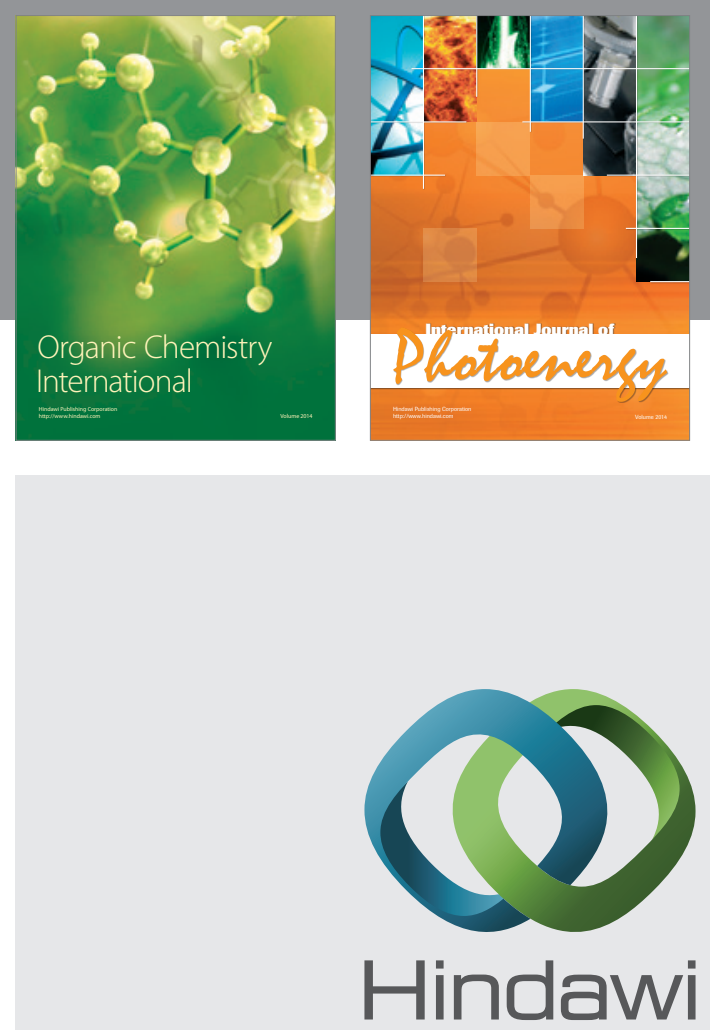

Submit your manuscripts at

http://www.hindawi.com
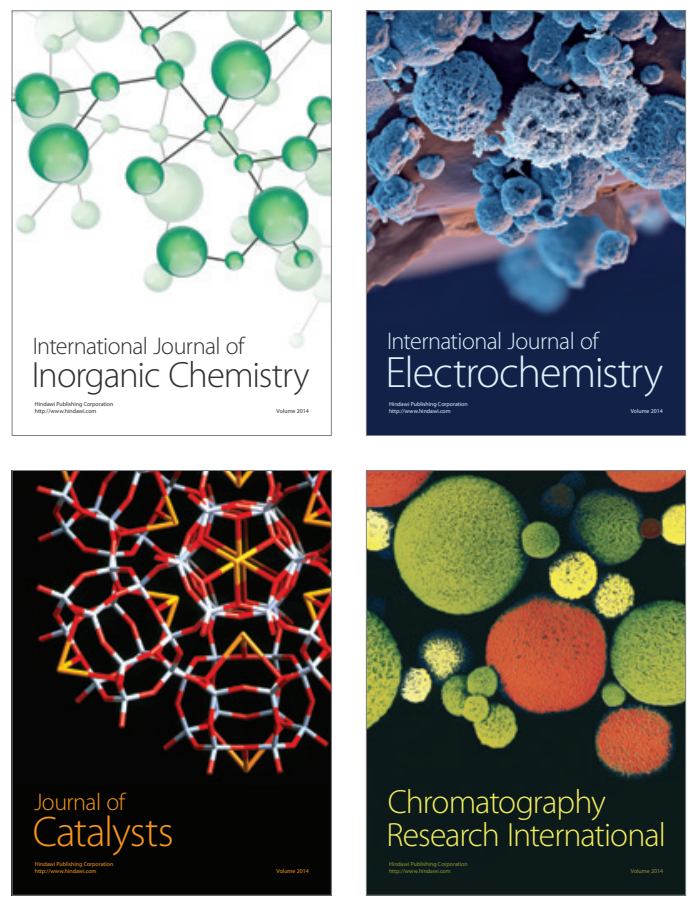
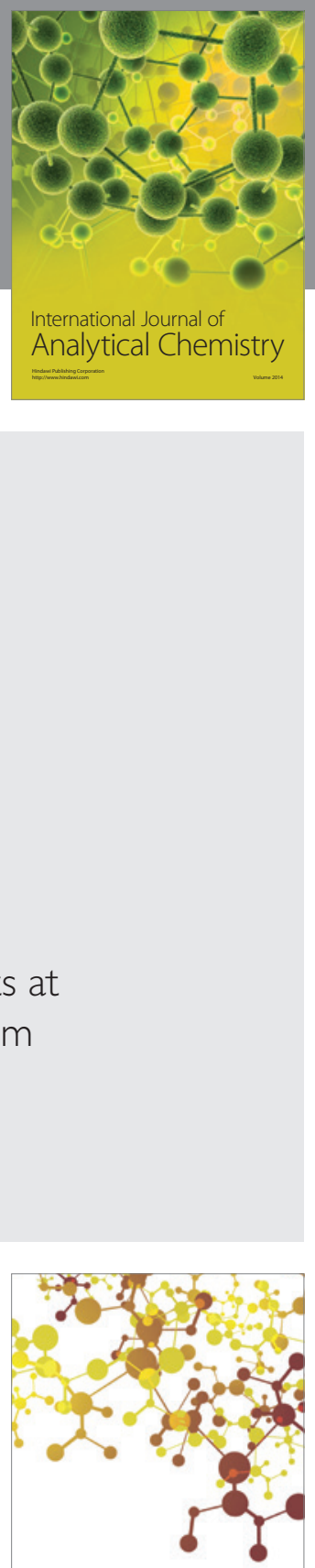

Journal of

Applied Chemistry
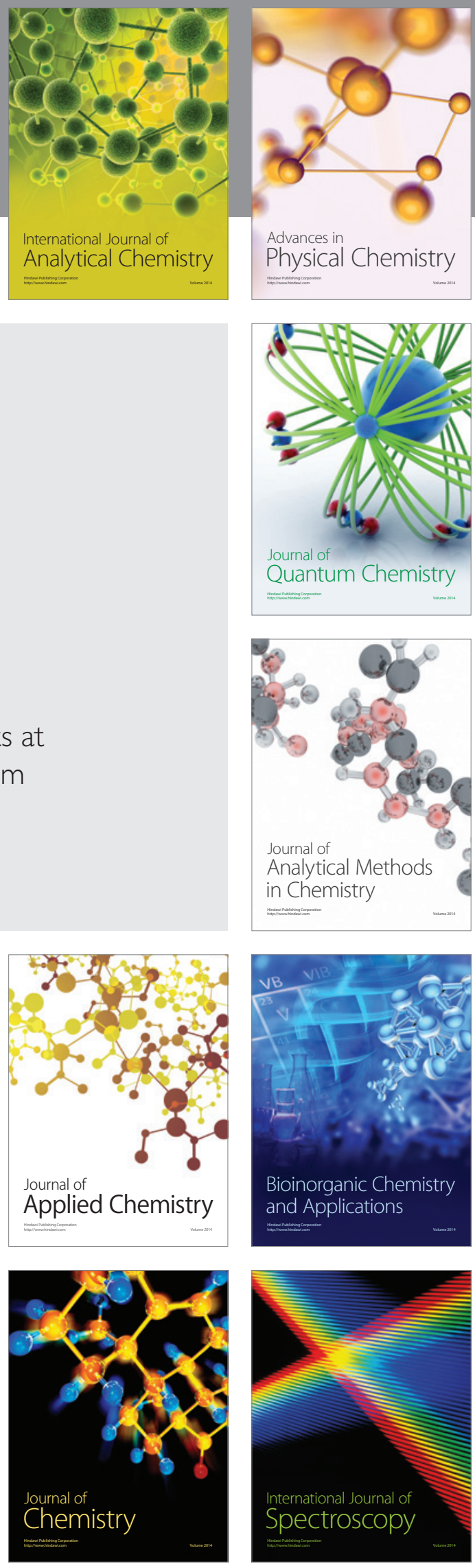